\title{
Apontamentos sobre a pedologia de Vigotski: alguns conceitos importantes em seu contexto histórico
}

\author{
Remarks on Vygotsky's pedology: some important concepts \\ in their historical context
}

Pabliny Marques de Aquino ${ }^{1}$

Gisele Toassa ${ }^{2}$

\begin{abstract}
RESUMO
Vigotski, na busca de compreender cientificamente a formação dos processos psicológicos tipicamente humanos, dialogou com a pedologia, ciência multidisciplinar que tinha como foco de estudo a criança. Considerando o comentário aos textos pedológicos do autor, este artigo tem por objetivo central compreender a mencionada ciência na perspectiva de Vigotski, em alguns de seus conceitos basilares. Exploramos, ainda, elementos da história da pedologia, além do Decreto de proibição à pedologia, que descrevemos brevemente. Trazemos resultados de pesquisas bibliográficas de textos de Vigotski traduzidos para o espanhol e para o português, tendo como corpus as obras presentes no Tomo IV, a publicação recente das "Sete aulas sobre pedologia". O texto descreve a pedologia e a forma como aborda o desenvolvimento, envolvendo a relação com os conceitos de periodização, crise, meio, consciência, personalidade, neoformação e vivências.
\end{abstract}

Palavras-chave: Pedologia. Consciência. Personalidade. Vigotski. Desenvolvimento humano.

\begin{abstract}
Vygotsky, seeking to scientifically understand the formation of typical human psychological processes, turned to pedology. This multidisciplinary science focused on the study of children. Relying upon the commentary on the author's pedological texts, this article aims to understand the aforementioned science from Vygotsky's perspective, in some of its basic concepts. We also explore elements of the history of pedology, as well as the Prohibition Decree against Pedology, which we describe briefly. In terms of method, this work was based on bibliographic research of Vygotsky's texts translated into Spanish and Portuguese, having as a corpus the pedological works presented in his Collected Works, the recent publication of the Seven Lessons on Pedology and works by Brazilian commentators. The results describe pedology, and how it approaches development. It also addresses its relationship with the concepts of periodization, crisis, environment, consciousness, personality, neoformation, and experiences.
\end{abstract}

Keywords: Pedology. Consciousness. Personality. Vygotsky. Human development.

\section{Introdução}

A Psicologia Histórico-Cultural é uma vertente da ciência psicológica, que surge no século XX, fortalecendo-se na União Soviética após a II Guerra Mundial. Em alguma medida, essa vertente esteve relacionada ao estudo de crianças,

\footnotetext{
${ }^{1}$ Estudante de graduação em Psicologia, Faculdade de Educação, Universidade Federal de Goiás. Bolsista do PICT (Programa Institucional de Iniciação Científica), Goiânia, Brasil. E-mail: pabliny.mda@gmail.com.

2 Professora do curso de psicologia, Faculdade de Educação, Universidade Federal de Goiás, Goiânia, Brasil. E-mail: gtoassa@yahoo.com.br.
} 
objeto da pedologia - ciência que começou a estabelecer-se na Rússia em 1907. Nesse ano, Bekhterev fundou o Instituto Psiconeurológico em São Petersburgo, nele trabalhando até o fim de seus dias, tendo o Instituto Psicopedológico como uma de suas subdivisões (VAN DER VEER; VALSINER, 2001). Considerando os marcos dos estudos pedológicos soviéticos, o presente artigo tem por objetivo contextualizar historicamente a pedologia de Vigotski, buscando, com isso, esclarecer alguns de seus conceitos mais populares no Brasil até nossos dias.

A pedologia foi agraciada com um Congresso (à época, inda denominado como Congresso de Pedagogia Experimental) e prédio próprio, na Rússia, já em 1911. O Instituto Psicopedológico foi incorporado pelo governo bolchevique ao Comissariado de Educação em 1918. Em 1920, passou à orientação da Diretoria de Ciência e da Academia Psiconeurológica (VAN DER VEER; VALSINER, 2001). O $2^{\circ}$ Congresso Psiconeurológico de Toda a Rússia, no qual debutou Vigotski, de fato chamava-se Congresso Russo sobre Pedologia, Pedagogia Experimental e Psiconeurologia - o que ilustra a força da área, além de sua conexão direta com a educação e a psiconeurologia.

Entre os vários periódicos científicos fundados no decorrer de 1928, um se intitulava Pedologia, o qual foi integrado ao planejamento quinquenal dos psicólogos, definindo seus objetivos a curto prazo (BAUER, 1952, p. 65) - sendo, igualmente, extinto junto de várias outras revistas especializadas relacionadas à psicologia, entre 1932-1934. O I Congresso de Toda a União sobre Pedologia, em 1927, contou com Lunacharsky, Krupskaia e Bukharin, nomes fortes da cúpula bolchevique. No início dos anos 1930s, alguns dos principais nomes da pedologia eram Blonski, Basov e Vigotski.

Desde o final do século XVIII, o território russo era marcado por movimentos sociais contrários ao Estado autocrático tzarista, que se apoiava na burocracia militar, civil e ideológica. Uma economia baseada na agricultura, e marcada pela desigualdade social. A decadência do Império impulsionou os movimentos revolucionários, entre os quais as correntes marxistas destacaramse, ganhando as massas, que passaram a direcionar as lutas, a política e a ciência. Tuleski descreve, no trecho a seguir, o contexto histórico em que nasce a teoria histórico-cultural: 
a história colocava para a sociedade russa pós-revolucionária a necessidade de encontrar os meios para sobreviver sem apoio e auxílio, convivendo, ainda, com ameaças militares, políticas e econômicas do ocidente. Um país enorme em proporções geográficas, com grande atraso econômico e cultural, arrasado pela guerra civil e pela guerra imperialista, deveria transformar-se em um curto espaço de tempo em um país capaz de produzir o suficiente para garantir a sobrevivência e satisfação da população, sob pena de mergulhar nas mais profundas barbáries (2008, p. 81).

No entanto, a ascensão de Stálin representa, em termos políticos, um giro autocrático. Como pontua Teixeira (2004), o governo stalinista foi marcado pela violência. O dissenso era punido com calúnia, prisão, tortura ou assassinatos, ou ainda as "autocríticas" públicas. Para além das transformações políticas e sociais, há uma reconfiguração obrigatória de toda a construção científica de acordo com as diretrizes stalinistas (LUKÁCS, 1977). A interpretação reducionista de Stálin sobre Marx torna-se referência obrigatória, no âmbito científico e cultural. Em sua "Carta sobre o stalinismo", Lukács salienta que Stálin modificou as teorias de Marx, Engels e Lênin como forma de justificar suas medidas no campo de um forte pragmatismo político. Stálin apoia-se na fusão entre Estado e partido, fortalecida pelo uso da propaganda como meio de inocular, nas massas, motivação para a construção do socialismo (SHUARE, 1990).

Como ressalta Teixeira (2004), não são raras as tentativas de banimento de ideias científicas ao longo da história. A pedologia foi um desses casos, sendo banida por Stálin em 1936 - um grande golpe para os psicólogos, muitos dos quais trabalhavam como pedólogos (VAN DER VEER; VALSINER, 2001), sendo vários deles vinculados a Vigotski.

Stálin erradicou a pedologia por meio do decreto "Sobre as deturpações pedológicas no sistema dos Narcompros", proibindo a produção de conhecimento na Pedologia até o fim da União Soviética, em 1991. Este período foi marcado por expulsões, prisões, demissões e destruição de materiais de produção científica (TOASSA, 2007).

De acordo com Shuare (1990), somente após 20 anos as obras vigotskianas voltaram a ser publicadas na Rússia. No Brasil, as traduções dos estudos de Vigotski chegaram a partir dos anos 1980s, advindas em sua maioria dos Estados 
Unidos, e exploradas principalmente por estudiosos da educação e da psicologia. Todavia, apesar da ampla popularidade da teoria, algumas obras (DUARTE, 1996; PRESTES; TUNES, 2011; TUNES; PRESTES; 2012) apontam diversas controvérsias nas traduções para a língua portuguesa, que acarretaram más interpretações de sua obra.

Vigotski visava a construir uma ciência sobre o homem que explicasse a gênese dos processos psicológicos tipicamente humanos (VAN DER VEER; VALSINER, 2001), e se voltou à infância para compreender esses processos. Nesta direção inclinava-se à pedologia, uma ciência abrangente e multidisciplinar, que compreendia o desenvolvimento infantil através de múltiplas áreas do conhecimento, trabalhando, assim, os aspectos biológicos, sociais, psicológicos, antropológicos, educacionais, patológicos etc. Por esta leitura menos fragmentada e este olhar multidisciplinar, a Pedologia traz discussões relevantes no conhecimento acerca do desenvolvimento humano, colocando a criança no centro das investigações.

Este trabalho é resultante de investigações realizadas no âmbito da iniciação científica da Universidade Federal de Goiás, buscando descrever ideias da teoria vigotskiana - algumas já muito conhecidas, como a de zona de desenvolvimento próximo - que constituem parte da teoria pedológica do autor, com prioridade, neste texto, aos conceitos de personalidade e consciência. Ademais, passamos pelas ideias de periodização, crise, meio, consciência, personalidade, neoformação e vivências.

Utilizamo-nos de comentadores para buscar compreender, de forma mais ampla, o sentido social da pedologia no contexto vigotskiano, promovendo, assim, maiores possibilidades de reconhecimento dos traços dessa ciência nas ideias desenvolvimentais constituídas pelo autor.

As pesquisas que possibilitaram a presente síntese integradora foram alicerçadas no TOMO IV das Obras Escogidas (VIGOTSKI, 2006e), uma obra que aglutina 14 textos pedológicos traduzidos para a língua espanhola. No entanto, para este trabalho nos concentramos nos textos relacionados à Psicologia $E l$ problema de la edad (VIGOTSKI, 2006g), El primer año (VIGOTSKI, 2006f), Crisis del primer año de vida (VIGOTSKI, 2006c), La infância temprana 
(VIGOTSKI, 2006d), Las crisis de los tres años (VIGOTSKI, 2006b), e La crisis de los siete años (VIGOTSKI, 2006a), esclarecidos por obras de comentadores.

\section{A ciência pedológica e seu desenvolvimento na URSS}

A pedologia foi um conhecimento interdisciplinar que tinha a criança como objeto de estudo principal. "Na tradução literal para a língua russa, pedologia significa "ciência da criança" (VIGOTSKI, 2018a, p. 17). Destinava-se a estudar os processos de desenvolvimento humano através da relação dialética entre os aspectos sociais, biológicos, psicológicos. Martins e Souza ressaltam que

podemos vislumbrar que a principal característica da proposta da pedologia está no fato de ela se organizar em torno de uma articulação entre pesquisadores de vários campos de conhecimento que tenham como principal objeto de estudo a criança. Isto significa dizer que o olhar do pesquisador deve estar localizado para além de seu campo de conhecimento, articulando os estudos de sua área com os de outros campos disciplinares (2018, p. 3).

A pedologia avaliava o desenvolvimento típico e atípico. Um editorial do Pedagogical Seminary (1892 apud MARTINS; SOUZA, 2018, p. 296) cita alguns temas considerados relevantes para a avaliação do desenvolvimento infantil. São eles:

A. Crescimento Físico. I. Peso [...] II. Medidas. III. Fotografia, Moldes etc. [...]

B. Teste Motores. [...] I. Testes Gerais. [...] II. Lista de Habilidades Especiais para Primeiro Grau. [...] III. Força. [...] IV. Rapidez. [...] V. Exatidão. [...] VI. Fadiga [...] VII. Linguagem. [...] C. Testando os Sentidos. [...]

D. Faculdades Mentais Superiores. Conteúdo das mentes das crianças. [...] E. Sentimentos e emoções.

F. Observações gerais.

G. Crianças defeituosas e excepcionais. [...]

H. Diversos.

Através dessas temáticas, pode-se compreender a amplitude das investigações pedológicas, a qual inclui o desenvolvimento psíquico e o orgânico simultaneamente. Prestes (2010) ressalta que o objetivo principal da pedologia era orientar os educadores através de uma ciência específica sobre a criança. A 
autora traz uma definição de pedologia desenvolvida por Vigotski e Varchava, expressas no dicionário de psicologia com publicação em 1931:

Pedologia - ciência da criança. O termo pedologia foi introduzido pelo cientista americano O. Rrisman (1893). O primeiro congresso de pedologia ocorreu em Buenos Aires, em 1926. A pedologia é uma ciência nova, que ainda não estabeleceu ao certo seus limites e seu objeto. Normalmente, ela é compreendida como uma ciência sobre o desenvolvimento da criança, abarcando todos os aspectos desse desenvolvimento - corporal e psíquico. Segundo Stanley Hall, ela abrange, em parte, a psicologia, em parte, a antropologia, em parte, a medicina e o higienismo; sua especificidade, segundo ele, está na concentração de muitas disciplinas científicas num objeto - a criança. Segundo Blonski, a pedologia é a ciência sobre o crescimento, a constituição e o comportamento da criança típica mais comum em diferentes épocas e fases da infância. Segundo Kornilov, a pedologia é uma disciplina científica das reações das crianças e dos fatores que determinam suas reações (VIGOTSKI; VARCHAVA, 2008 apud PRESTES, 2010, p. 51).

Desse modo, os estudos da pedologia no território russo são anteriores ao período de revolução, iniciado em 1917. De acordo com van der Veer e Valsiner (2001), o Instituto contava com diversos estudiosos russos importantes, e tinha como objeto principal de estudo a pedologia da primeira infância. A estruturação e organização do espaço passou por diversas mudanças. Fundado em 1907 no Instituto Psiconeurológico, ganhou o seu próprio prédio somente em 1911. Seis anos depois deixou de funcionar devido a dificuldades políticas e econômicas do período histórico revolucionário. Entretanto, os estudos relacionados à disciplina continuam a se expandir.

De 1920 até meados de 1930 houve expansão da literatura pedológica russa. Os estudos são instigados pelo interesse na reconstrução social e cultural na Rússia pós-revolução, com o intuito de criação de uma nova sociedade, organizada de acordo com os princípios socialistas. A pedologia, neste momento, é tida como uma disciplina que auxiliaria no processo de implementação de novos métodos pedagógicos que pudessem responder aos ideais impostos pelo Estado. Como afirmam van der Veer e Valsiner (2001, p. 323): "O desenvolvimento da pedologia na URSS esteve fortemente associado a esses esforços pedagógicos e ideológicos". 
Há formidável impulso do final dos anos 1920/início dos 1930, quando a pesquisa pedológica e suas aplicações ao sistema educacional, bem como a psicotécnica (psicologia aplicada ao trabalho), passaram a ser tomadas como disciplinas que atendiam aos slogans stalinistas sobre o valor da prática. Floresceu a aplicação de testes como método de promover o encontro entre os talentos individuais e os postos de trabalho/educação disponibilizados pelo Estado (JORAVSKY, 1989).

Com as bênçãos do Estado soviético, os pedólogos tinham como objetivo “(...) determinar as causas do escasso progresso de certos alunos, dirigir a educação política, determinar a posição futura dos alunos próximos de graduarem-se em trabalhos adequados à sua vocação, eliminar os alunos incapazes de suportar suas tarefas etc.” (TEIXEIRA, 2004, p. 236).

No entanto, Bauer (1952) aponta que, na visão do regime, diversos pedólogos realizavam práticas indiscriminadas, como aplicação de testes de inteligências sem padronização. Também existia uma rivalidade entre pedagogos e pedólogos, impulsionada pela ampla inserção destes últimos nas escolas, enviando grande quantidade de estudantes para classes especiais, cuja estrutura algo individualizante, de modo geral, não se adequava ao espírito igualitário do socialismo (JORAVSKY, 1989). Este controle resultou também, em uma desvinculação da pedologia com relação ao saber pedagógico. Sobre isso, Teixeira (2004, p. 237) pontua que

(...) a prática pedológica, que se desenvolveu por completo fora de um contato com os professores e os estudos escolares, estava basicamente fundada em experimentos pseudocientíficos e numa série interminável de insensatos e prejudiciais questionários e provas de investigação que se realizavam com os alunos e seus pais.

O decreto sobre as deturpações pedológicas no sistema dos Narcompros $^{3}$, promulgado pelo Comitê Central do Partido Comunista Soviético (CC do PCR) em 4 de julho de 1936, foi publicado pelo jornal Pravda - o de maior circulação da União Soviética. O conteúdo do decreto traz diversas justificativas para proibir a prática e os estudos dos pedólogos na Rússia. Expõe o serviço da pedologia como 
desnecessário à construção de um estudo marxista sobre as crianças. De modo bastante controverso, considera que os métodos são anticientíficos, e serviriam apenas aos ideais das classes dominantes. O seguinte trecho foi retirado desta resolução, e permite evidenciar as justificativas do CC do PCR para a proibição da pedologia (PRESTES, 2010, anexo 2), na qual o

dano foi profundo pelo caráter e pela metodologia do trabalho pedológico na escola. A prática dos pedólogos, que ocorria sem nenhuma relação com o pedagogo e as atividades escolares, reduziu-se a experimentos cientificamente falsos e à realização, entre os escolares e seus parentes, de uma infinita quantidade de estudos em forma de questionários e testes sem sentido, nocivos, etc., que há muito foram condenados pelo partido. Esses ditos "estudos" científicos, realizados com um grande número de estudantes e seus pais, eram direcionados, predominantemente, contra aqueles que tinham mau aproveitamento ou aqueles que não se enquadravam no regime escolar. Os métodos dos pedólogos tinham por objetivo provar, do ponto de vista "científico" e "biossocial" da pedologia contemporânea, a condicionalidade hereditária e social do mau aproveitamento do estudante ou de alguns defeitos em seu comportamento, como também, encontrar o máximo de influências negativas e de transtornos patológicos no próprio estudante, sua família, parentes, antecedentes e meio social e, com isso, encontrar motivos para a expulsão de estudantes do coletivo escolar normal (COMITÊ CENTRAL DO PARTIDO COMUNISTA DA URSS, 1936/2010, p. 205-206).

A pedologia era, então, uma ciência bastante diversificada, sendo muitas as razões para sua eliminação, e não apenas os alegados no Decreto. Como afirma Toassa: "algumas pesquisas mostravam as reais dinâmicas sociais existentes na heterogênea sociedade russa, os seus problemas, de forma contrária à imagem que o regime desejava projetar" (2007, p. 264). A partir de Bauer (1952) e Joravsky (1989), é possível afirmar que, enquanto a propaganda alardeava resultados positivos sobre a educação soviética, pesquisas pedológicas e da psicologia apontavam no sentido contrário.

Após a publicação desse decreto, a pedologia foi banida do território soviético. De acordo com Leontiev (2005 apud Toassa, 2007), após esse período houve diversas expulsões, demissões e destruição de textos científicos. Para van der Veer e Valsiner (2001, p. 320), essa medida foi, sem dúvida "um dos principais efeitos do stalinismo sobre a psicologia”. As consequências deste 
decreto repercutem ainda hoje, trazendo implicações nos estudos da teoria vigotskiana, principalmente quando foco é a pedologia e seus conceitos basilares que, por boa parte dos leitores, não são reconhecidos enquanto tal.

Todavia, por 20 anos após esse decreto, as obras pedológicas de Vigotski ficaram sob a tutela dos seus discípulos, e devido à proibição, algumas poucas ainda circulavam de forma clandestina. Um movimento de reedição do autor só foi retomado a partir de 1956, com a nova publicação, em russo, do livro Pensamento e Linguagem (TEIXEIRA, 2004).

Toassa e Delari Junior (2013) pontuam que a psicologia histórico-cultural, de fato, era avessa a algumas práticas psicométricas utilizadas. O autor russo compreendia teoricamente a importância de avaliar as crianças, em suas capacidades de realização de atividades individuais, mas em direção distinta com relação às avaliações que eram feitas. Ressaltava a importância de se avaliar também, as capacidades que emergiam a partir das relações dos aprendizes com seus pares, e com pessoas mais experientes. Defendia uma avaliação do desenvolvimento psíquico como um todo, e negava a dicotomização das funções psíquicas, como exemplo, as funções afetivas e cognitivas (TOASSA; DELARI JÚNIOR, 2013). No texto El problema de la edad (VIGOTSKI, 2006g), Vigotski propõe uma avaliação do desenvolvimento psicológico a partir de seu aspecto holístico, ressaltando assim o seu posicionamento acerca desta questão, evidenciando a importância de se investigar o que está oculto, o próprio processo do desenvolvimento infantil e suas leis internas.

Sabemos que a idade cronológica da criança não pode servir como critério seguro para estabelecer o nível real do seu desenvolvimento. Por isso, a determinação do nível real do seu desenvolvimento exige sempre uma investigação especial graças à qual pode ser elaborado o diagnóstico do desenvolvimento. Estabelecer o nível real de desenvolvimento é uma tarefa essencial e indispensável para a solução de todas as questões práticas relacionadas com a educação e o aprendizado da criança, com o controle do curso normal de seu desenvolvimento físico e mental e o diagnóstico de outras alterações do desenvolvimento que perturbam a trajetória normal e conferem ao processo um caráter atípico, anormal e, as vezes, patológico (VIGOTSKI, 2006g, p. 265256, tradução nossa). 
Neste trecho, fica claro o posicionamento de Vigotski acerca da avaliação das crianças. Vigotski afirma que a lei básica do desenvolvimento é a diferença do tempo de maturação das diversas facetas da personalidade em suas distintas propriedades; um autêntico diagnóstico deve abarcar os ciclos já alcançados, sendo que muitos processos mentais estão em fase de maturação e dependem da mediação de sujeitos mais experientes; com isso, se forjou a ideia de zona de desenvolvimento imediato (VIGOTSKI, 2006g). Esta tese possibilitou a superação de avaliações baseadas em compreensões inatistas, que partiam da ideia de inteligência como talento ou dom (TOASSA; DELARI JÚNIOR, 2013). Mas antes de se compreender o método de avaliação instituído pelo autor, tornase necessário apresentar os estudos pedológicos desenvolvidos em sua teoria.

\section{Pedologia em Vigotski e sua compreensão do desenvolvimento humano}

Vigotski teve um interesse precoce nos estudos em pedologia. Seu contato teórico-prático com a disciplina é permeado por trabalhos experimentais e da prática clínica. Na concepção do autor, a pedologia seria uma síntese das várias disciplinas que tinham como enfoque os estudos da criança, incluindo, também, a psicologia infantil (TOASSA, 2009).

O psicólogo russo priorizava a infância, na tentativa de compreender os processos do desenvolvimento, pois nesse momento vital consolidam-se os primórdios da história humana e a gênese das funções psíquicas superiores. De acordo com van der Veer e Valsiner (2001), a pedologia é meio no qual Vigotski realiza seu objetivo de compreender o desenvolvimento humano de forma ampla, incluindo, nisso, as crianças portadoras de necessidades especiais.

Para o autor, seria necessário mudança radical que superasse as limitações metodológicas da psicologia infantil; dessa maneira, propõe a utilização do método genético-experimental. Além disso, a metodologia pedológica vigotskiana enfatiza análise estrutural em unidades e análise de elementos (VAN DER VEER; VALSINER, 2001; TOASSA, 2009).

O autor sublinhou o caráter holístico, clínico e genético comparativo do método pedológico (VIGOTSKI, 2018a). LSV aponta que "o desenvolvimento da 
criança é o objeto direto e imediato" da ciência pedológica (VIGOTSKI, 2018a, p. 17), mas não exclui o caráter interdisciplinar desse campo de estudo. Mas como o desenvolvimento humano é compreendido neste enfoque?

O desenvolvimento, para a teoria histórico-cultural, é processo biossocial (YASNITSKY, 2011), um movimento dinâmico, de evoluções e involuções, que leva em consideração o contexto histórico, social, cultural e biológico. É marcado por mudanças qualitativas, quantitativas e estruturais.

(...) Se trata de um complexo dialético que se distingue por uma complicada periodicidade, a desproporção no desenvolvimento das diversas funções, as metamorfoses ou transformação qualitativa de umas formas em outras, um entrelaçamento complexo de processos evolutivos e involutivos, o complexo cruzamento de fatores externos e internos, um complexo processo de superação de dificuldades e de adaptação (VIGOTSKI, 1995, p. 141, tradução nossa).

$\mathrm{Na}$ teoria vigotskiana, o desenvolvimento é tido como o curso de constituição da personalidade e consciência humana - daquilo que nos torna especificamente humanos - bem como das funções psíquicas parciais que as compõem. A personalidade é compreendida como um conjunto de "aspectos diferenciadores dos sujeitos no interior de uma cultura ou grupo particular" (TOASSA, 2009, p. 232). São mudanças microscópicas que ocorrem principalmente nas idades estáveis, e vão se acumulando e se apresentando como novos processos mentais, as neoformações (VIGOTSKI, 2006g).

Vigotski (2018b) pontua que os estudos teóricos sobre o desenvolvimento da personalidade, por vezes, eram carregados de equívocos metodológicos e teóricos. Neste movimento, as funções psíquicas eram tidas como processos isolados.

Em relação ao desenvolvimento psicológico da criança, durante muito tempo, essa regularidade estava fora da atenção dos pesquisadores. A psique do homem era apresentada como uma formação complexa. Naturalmente, essa psique começou a ser desmembrada com o objetivo de estudá-la cientificamente, distinguindo-se determinadas funções psicológicas, digamos, memória, atenção, pensamento, vontade, emoção etc. Quando essa antiga psicologia funcional abordava o problema do desenvolvimento infantil, ela pensava que as funções psicológicas se desenvolviam separadamente e que as relações entre elas não se desenvolviam, permaneciam inalteradas. Isso é um grande 
equívoco e se configura como um obstáculo na ciência do desenvolvimento psicológico da criança (VIGOTSKI, 2018b, p. 94).

Vigotski desenvolve uma teoria em um movimento contrário à "antiga psicologia”. Van der Veer e Valsiner (2001) salientam a preocupação vigotskiana com o método de análise por unidades, constituído por uma posição teórica orientada contra a fragmentação do psiquismo em elementos sem estrutura interna. Para o autor, há tanto relação entre as próprias funções psicológicas, quanto entre as unidades elementares de uma mesma função.

No entanto, como pontuado por Toassa (2009), há dificuldade na definição da ideia de sistema psicológico na teoria histórico-cultural. "A rigor, sistema é mais um princípio geral que um conceito rigorosamente definido" (p. 226). Frisase que a criação desses sistemas se dá nos limites e possibilidades do organismo, e são formadas, em grande medida, em sociedade. Desses sistemas psicológicos em relação com o mundo, a personalidade, a consciência e autoconsciência são os mais complexos.

A consciência se desdobra em três compreensões, na teoria vigotskiana: a) a consciência é tida como um processo e seu produto, a tomada de consciência, b) um atributo, que qualifica diversas funções ou conteúdos psíquicos (assim consideramos, por exemplo, a existência de "perceptos" ou "memórias" conscientes), c) um sistema psicológico do sujeito em relação com o meio e consigo próprio (TOASSA, 2009).

Em síntese, o desenvolvimento humano é compreendido como a constituição dialética das características essencialmente humanas. Este processo é caracterizado por diversas mudanças qualitativas, que ocorrem em um curso histórico e cultural. Cada mudança possui íntima relação com os processos ocorridos em uma fase anterior do desenvolvimento. Podemos compreender esse processo como um circuito de mudanças e transformações qualitativas, nas quais o desenvolvimento do todo influi no das partes (VIGOTSKI, 2018a).

O desenvolvimento é um processo contínuo de automovimento, que se distingue, em primeiro lugar, por uma permanente aparição e formação do novo, que não existe em estados anteriores. Esse ponto de vista sabe captar no desenvolvimento algo essencial para 
a compreensão dialética do processo (VIGOTSKI, 2006g, p. 254, tradução nossa).

Em cada fase surge algo absolutamente novo, uma nova estrutura que constitui o novo estágio, o que Vigotski definiu como neoformação. As neoformações são estruturas que modificam as funções psíquicas, e o contato da criança com o mundo exterior e interior. Ressaltando o caráter dinâmico do processo de desenvolvimento, elas assumem a função de critério fundamental para a classificação do desenvolvimento infantil em diversas idades e etapas (MESHCHERYAKOV, 2010).

Entendemos por neoformações o novo tipo de estrutura da personalidade e sua atividade nas mudanças psíquicas e sociais que se produzem pela primeira vez em cada idade e determinam o aspecto mais importante e fundamental, ou seja, a consciência da criança, sua relação com o meio, sua vida interna e externa, todo o curso de seu desenvolvimento no período dado (VIGOTSKI, 2006g, p. 256, tradução nossa).

O desenvolvimento ocorre em uma sucessão de idades estáveis e momentos de crises. Nas idades estáveis ocorrem mudanças microscópicas na personalidade da criança. Transformações que vão se acumulando em um longo espaço de tempo, e se expressam em neoformações. "Cada idade possui sua própria estrutura específica, única e irrepetível” (VIGOTSKI, 2006g, p. 262, tradução nossa). As crises são caracterizadas pelas mudanças repentinas na personalidade da criança, podendo levar a um desencontro entre suas capacidades reais e as expectativas de seu meio. De modo geral, na União Soviética, manifestavam-se no primeiro ano de vida; e também aos três, aos sete, e, finalmente, aos treze anos.

Com relação à temporalidade, o desenvolvimento ocorre de maneira complexa, havendo períodos de aceleração na atribuição qualitativa de novas estruturas, e sucessão de período de desaceleração e retração. Embora em geral transcorra de forma cíclica, apresenta irregularidades, sendo que cada função/processo psicológico tem seu próprio curso, e momento propício para se desenvolver - existindo "dissincronias desenvolvimentais". Para compreendermos isso, tomemos como exemplo o desenvolvimento físico e mental: ambos fazem parte do processo de crescimento infantil, entretanto, não há como afirmar que os 
processos mentais se desenvolvam da mesma forma e no mesmo período que os físicos. Portanto, há irregularidades em diferentes funções, apesar de existir íntima relação entre elas (VIGOTSKI, 2018a).

Vigotski deixou inacabada sua teoria de periodização, a qual compreende as idades como ciclos, diferenciadas por seu tempo e conteúdo específicos. Cada ciclo é marcado por uma função mais conspícua no desenvolvimento: "Em cada uma das etapas a criança se apresenta como um ser qualitativamente específico que vive e se desenvolve segundo leis diferentes próprias de cada idade" (VIGOTSKI, 2018a, p. 30).

A tese mais geral é que o processo de desenvolvimento em cada idade, toda a complexidade de sua organização, composição e multiplicidade dos processos parciais que o integram constituem um todo único e possuem estrutura determinada. As leis que regem a formação desse todo, ou as leis estruturais de cada idade, determinam a estrutura e o curso dos processos de desenvolvimento particular que formam parte do todo. Vigotski chama de estruturas a tais formações globais, nas quais se arranjam o destino e o significado de cada parte (VIGOTSKI, 2006g).

Ao falarmos de desenvolvimento infantil em uma compreensão vigotskiana, precisamos evidenciar a importância do meio, pois, além dos conceitos basilares que regem o processo de desenvolvimento, apresentados acima, este movimento é antes de tudo social, sendo mediado pelo meio e pelo contato da criança com a cultura.

Conforme disposto em uma conferência já muito popular no Brasil (VIGOTSKI, 2010), o meio tem um caráter variável e dinâmico. Tem o papel de fonte de desenvolvimento das características especificamente humanas, como processo histórico e cultural. Nele, apresenta-se a forma ideal que serve de modelo para a criança atingir ao final do processo de desenvolvimento; com o qual ela interage desde nascer. Segundo LSV, a "relação da criança com a realidade circundante é social desde seu princípio" (VIGOTSKI, 2006f, p. 285, tradução nossa).

O meio desempenha no desenvolvimento da criança, no que se refere ao desenvolvimento da personalidade e de suas características específicas ao homem, o papel de uma fonte de 
desenvolvimento, ou seja, o meio, nesse caso, desempenha o papel não de circunstância, mas de fonte de desenvolvimento (VIGOTSKI, 2010, p. 69, tradução nossa).

No processo de desenvolvimento, o meio físico, bem como os sociais nos quais ele ganha sentido e se humaniza, vão se ampliando, e mesmo se não houver mudanças objetivas tão evidentes, o modo como a criança o vivencia vai se modificando de acordo com sua experiência humana e desenvolvimento biológico (VIGOTSKI, 2010).

Aos pedólogos cabe a investigação do meio em aspectos relativos ao desenvolvimento da criança, em suas facetas afetiva, perceptiva e sensitiva, levando em consideração as particularidades de cada criança. Pois, para LSV, "a relação entre a criança e o meio não é jamais uma relação puramente externa" (VIGOTSKI, 2006a, p.382, tradução nossa). Não cabe estudar meramente o meio físico e as regras que o constituem, mas o seu papel, o sentido atribuído pela criança, e a participação deste em seu desenvolvimento (VIGOTSKI, 2010). O que ressalta importância da compreensão do conceito de vivência na teoria vigotskiana.

A vivência nos revela como os aspectos culturais influem no desenvolvimento de determinada criança, sendo está "a unidade para o estudo da personalidade e do meio" (VIGOTSKI, 2006f, p.383, tradução nossa). Em outro texto, afirma ainda que

A vivência é uma unidade na qual, por um lado, de modo indivisível, o meio, aquilo que se vivencia está representado - a vivência sempre se liga àquilo que está localizado fora da pessoa e, por outro lado, está representado como eu vivencio isso, ou seja, todas as particularidades da personalidade e todas as particularidades do meio são apresentadas na vivência, tanto aquilo que é retirado do meio, todos os elementos que possuem relação com dada personalidade, como aquilo que é retirado da personalidade, todos os traços de seu caráter, traços constitutivos que possuem relação com dado acontecimento. Dessa forma, na vivência, nós sempre lidamos com a união indivisível das particularidades da personalidade e das particularidades da situação representada na vivência (VIGOTSKI, 2010, p. 686).

$\mathrm{Na}$ unidade da vivência são ressaltadas as particularidades da personalidade, e é por intermédio dela que o meio exerce influência sobre o 
desenvolvimento. Além disso, o meio irá influenciar no desenvolvimento da criança, dependendo, também, da tomada de consciência, ou seja, da forma pela qual a criança compreende os aspectos sociais e os elementos da realidade circundante. Isso se faz importante nos processos educacionais, pois cada criança o apreende à sua maneira, de acordo com suas particularidades (VIGOTSKI, 2010).

Vigotski se utiliza do conceito de "zona de desenvolvimento imediato" termo com o qual Bezerra (2001) substitui a estranha tradução "zona de desenvolvimento proximal" - como forma de demonstrar que, a partir da interação e mediação dos processos culturais, a criança pode aprender, e, simultaneamente, desenvolver-se. Este conceito, já tão conhecido pelos estudiosos brasileiros, ressalta o aspecto social desse processo de humanização e constituição da personalidade e da consciência.

\section{Considerações finais}

Este trabalho teve como objetivo debater, de modo introdutório, a pedologia vigotskiana, expondo os conceitos pedológicos, e a compreensão de desenvolvimento humano para o autor. Expusemos brevemente o desenvolvimento da pedologia na União Soviética, colocando em questão as contradições sociais e históricas presentes no stalinismo. A ascensão de Stálin modifica drasticamente todo contexto soviético, marcando o desenvolvimento da Pedologia.

Buscou-se delinear o contexto histórico que possibilitou a construção da pedologia soviética, e de seu banimento, bem como o reconhecimento de importantes conceitos vigotskianos - alguns dos quais já bastante difundidos no Brasil - como pedológicos.

Em sua pedologia, Vigotski compreende a criança como ativa em todo o processo de desenvolvimento, e defende que todas as funções psicológicas superiores, essencialmente humanas, se desenvolvem no contato social e dinâmico. O processo é direcionado pelo modelo ideal que deve ser alcançado ao 
final de infância, o qual se apresenta no meio social desde o princípio. Portanto, o meio aqui é tido como a fonte de desenvolvimento da personalidade, da consciência e das particularidades essencialmente humanas e desenvolvidas ao longo da história.

\section{Referências}

BAUER, R. The new man in soviet psychology. Boston: Harvard University Press, 1952.

BEZERRA, P. Prólogo do tradutor. In: A construção do pensamento e da linguagem. São Paulo: Martins Fontes, 2001, p. VII-XIV.

COMITÊ CENTRAL DO PARTIDO COMUNISTA DA URSS. Resolução do CC do PCR (b), de 4 de julho de 1936. Sobre as deturpações pedológicas no sistema do Narkompros. 1936. In: PRESTES, Z. R. Quando não é quase a mesma coisa: análise de traduções de Lev Semionovitch Vigotski no Brasil - repercussões no campo educacional. Tese (Doutorado em Educação), Faculdade de Educação da Universidade de Brasília, Brasília, p. 205-208, 2010.

JORAVSKY, D. Russian psychology: a critical history. Oxford: Blackwell UK, 1989.

MARTINS, J. M.; SOUZA. M. P. R. Pedologia de Vigotski e a abordagem multirreferencial: Aproximações. Revista Interamericana de Psicologia, v. 52, n. 3, p.295-305, 2018.

LEONTIEV, A. A. The Life and Creative Path of A.N. Leontiev. Journal of Russian and East European Psychology, vol. 43, n. 3, p. 8-69, 2005.

MESHCHERYAKOV, B. G. Ideias de L.S. Vigotski sobre a ciência do desenvolvimento infantil. Psicologia USP, v. 21, n. 4, p. 703-726, 2010.

PRESTES, Z. Quando não é quase a mesma coisa: análise de traduções de Lev Semionovitch Vigotski no Brasil - repercussões no campo educacional. 2010. Tese (Doutorado). Faculdade de Educação da Universidade de Brasília, Brasília, 2010.

PRESTES, Z; TUNES, E. Notas biográficas e bibliográficas sobre L. S. Vigotski. Universitas: Ciências da Saúde, Brasília, v. 9, n. 1, p. 101-135, jan./jun. 2011.

PRESTES, Z; TUNES, E. A trajetória de obras de Vigotski: um longo percurso até os originais. Estudos de Psicologia, Pontifícia Universidade Católica de Campinas, v. 29, n. 3, p. 327-340, jul-set, 2012.

SHUARE, M. La psicología soviética tal como yo la veo. Moscou: Progresso, 1990. 
TEIXEIRA, E. S. Censura imposta a Vigotski e seus colegas na União Soviética entre 1936 e 1956: o decreto da pedologia. Revista Científica in Pauta, II, p. 222$244,2004$.

TOASSA, G. A vida emocional na psicologia soviética: Vigotski, Rubinstein e Leontiev. Qualificação (Doutorado em Psicologia Escolar e do Desenvolvimento Humano). Instituto de Psicologia, Universidade de São Paulo, São Paulo.

TOASSA, G. Emoções e vivências em Vigotski: investigação para uma perspectiva histórico-cultural. 2009. Tese (Doutorado em Psicologia Escolar e do Desenvolvimento Humano). Instituto de Psicologia, Universidade de São Paulo, São Paulo, 2009.

TOASSA, G.; DELARI JÚNIOR, A. Sakharov e os métodos para pesquisa da formação de conceitos. Fractal: Revista de Psicologia, Rio de Janeiro, v. 25, n. 3, p. 645-658, Set./Dez, 2013.

TULESKI, S. S. Vygotsky: a construção de uma psicologia marxista. 2. ed. Maringá: EDUEM, 2008.

VAN DER VEER, R.; VALSINER, J. Vygotsky: uma síntese. 4. ed. São Paulo: Loyola/ Unimarco, 2001.

VIGOTSKI, L. S. Génesis de las funciones psíquicas superiores. In: Obras escogidas. Madrid: Visor Distribuciones. 1931/1995. iii, p.136-167.

La crisis de los siete años. In: Obras Escogidas. 2. ed. Madrid: Machado Libros, 1933-1934/2006a. iv, p. 377-386.

La crisis de los tres años. In: Obras Escogidas. 2. ed. Madrid: Machado Libros, 1933-1934/2006b. iv, p.369-375.

Crisis del primer año de vida. In: Obras Escogidas. 2. ed. Madrid: Machado Libros, 1933-1934/2006c. iv, p.319-340.

La infancia temprana. In: Obras Escogidas. 2. ed. Madrid: Machado Libros, 1933-1934/2006d. iv, p.341-367.

Obras Escogidas. 2. ed. Madrid: Machado Libros, 2006e. iv.

El primer año. In: Obras Escogidas. 2. ed. Madrid: Machado Libros, Tomo IV, 1932-1934/2006f. iv, p. 275-318.

El problema de la edad. In: Obras escogidas. 2. ed. Madrid: Machado Libros. 1932-1934/2006g. iv, p. 251-274.

VIGOTSKI, L. S. Quarta aula: a questão do meio na pedologia. Psicologia USP, São Paulo, v. 21, n. 4, jan. 1935/2010, p. 681-701. 
. Primeira aula: o objeto da pedologia. In: Sete aulas de L.S. Vigotski sobre os fundamentos da pedologia. Rio de Janeiro: E-papers. 1935/2018a. p. 17-36.

Quinta aula: Leis gerais do desenvolvimento do desenvolvimento psicológico da criança. In: Sete aulas de L.S. Vigotski sobre os fundamentos da pedologia. Rio de Janeiro: E-papers. 1935/2018b. p.92-108.

YASNITSKY, A. O Vigotski que nós (não) conhecemos: os principais trabalhos de Vigotski e a cronologia de sua composição, n.4, 2011. ISSN 2076-7099. p. 62-70. 